\title{
QUALIFIED ASSISTANCE IN RESOLVING DISPUTES RELATED TO LAND USE
}

\author{
Oksana I. Sharno \\ Volgograd State University, Volgograd, Russian Federation
}

\begin{abstract}
Anna Yu. Chikildina
Volgograd Institute of Management - Branch of the Russian Presidential Academy of National Economy and Public Administration, Volgograd, Russian Federation
\end{abstract}

Introduction: in this article, the authors analyze the issue of systematization of legal disputes in the field of land use, argues the conclusion about the importance of having qualifications among those who provide legal assistance in law enforcement practice in resolving land conflicts. Purpose: it is necessary to conduct a study of qualified assistance in the resolution of disputes relating to land use. Results: the authors considered in detail the issue of qualified assistance in the context of resolving land disputes, given conclusions of theoretical and practical significance. Conclusions: in the resolution of disputes related to land use, protection (representation) of the rights and legitimate interests of individuals and legal entities lies with corporate lawyers and lawyers, and qualified assistance is provided by specialists with theoretical and practical experience in land use.

Key words: the land plot, a land dispute, specialized court, the qualified legal aid, lawyer activity.

Citation. Sharno O.I., Chikildina A.Yu. Qualified Assistance in Resolving Disputes Related to Land Use. Legal Concept, 2019, vol. 18, no. 1, pp. 63-70. (in Russian). DOI: https://doi.org/10.15688/lc.jvolsu.2019.1.8

\section{КВАЛИФИЦИРОВАННАЯ ПОМОЩЬ ПРИ РАЗРЕШЕНИИ СПОРОВ, СВЯЗАННЫХ С ЗЕМЛЕПОЛЬЗОВАНИЕМ}

\author{
Оксана Игоревна Шарно
}

Волгоградский государственный университет, г. Волгоград, Российская Федерация

\section{Анна Юрьевна Чикильдина}

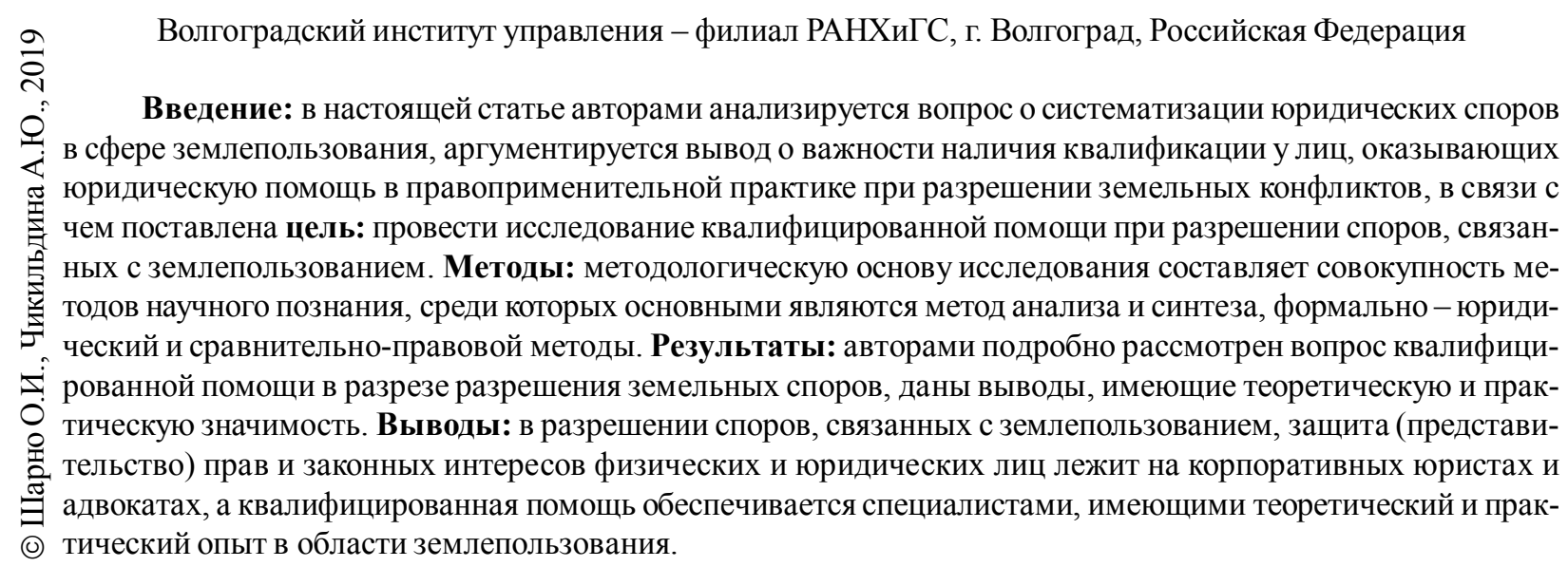


Ключевые слова: земельный участок, земельный спор, специализированный суд, квалифицированная юридическая помощь, адвокатская деятельность.

Цитирование. Шарно О. И., Чикильдина А. Ю. Квалифицированная помощь при разрешении споров, связанных с землепользованием // Legal Concept = Правовая парадигма. $-2019 .-$ T. 18, № 1. - C. 63-70. - DOI: https://doi.org/10.15688/lc.jvolsu.2019.1.8

\section{Введение}

Настоящее исследование базируется на следующих тезисах. Земля - это специфический, существенный объект права, поэтому эффективность разрешения связанных с ней споров требует теоретико-практического осмысления. Актуальность земельных споров в судебной практике и доктрине земельного права обусловлена их повышенной сложностью, конфликтностью, особенностями регулирования и разрешения, сопряжена с реформированием земельного законодательства. Для целей настоящего исследования под земельным спором мы понимаем конфликт, столкновение интересов сторон, возникших в процессе землепользования. Эффективность разрешения споров, связанных с землепользованием, достигается за счет обеспечения участников земельных споров квалифицированной помощью, в том числе юридической, все более востребованной в современных условиях разрешения земельно-правовых конфликтов.

\section{Основное содержание}

Изменения федерального законодательства по вопросам землепользования и кадастрового учета $[3 ; 4 ; 7 ; 16 ; 17]$, поправки, коснувшиеся вопросов земельно-правового и градостроительного регулирования регионального и местного значения, существенным образом затронули, а в некоторых случаях изменили, правоприменительную практику разрешения споров, связанных с землепользованием. Так, говоря о специфике определения границ земельных участков, стоит вспомнить, что еще несколько лет назад судебная практика по данной категории дел складывалась в двух направлениях: в одних случаях при разрешении споров, связанных с защитой права собственности и других вещных прав, юридически значимым обстоятельством служили исторически сложившиеся границы земельных участков, в других - границы, установленные в соответствии с действующим законодательством. В настоящее время позиции Верховного суда РФ [14] закрепляют путем официального толкования норм в процессе их применения, что юридические, то есть установленные в соответствии с действующим законодательством (не фактические) границы, внесенные в кадастр недвижимости и не оспоренные по основанию наличия кадастровых ошибок, являются законными, даже если они отличаются от границ участков, сложившихся в ходе их фактического использования. Появилась возможность защиты прав землепользователей в вопросах установления границ земельных участков. Например, в соответствии с Федеральным законом «О кадастровой деятельности» [16] введена и нормативно закреплена ответственность кадастровых инженеров, осуществляющих работу по установлению и определению местоположения границ земельных участков. Изменилась и специфика разрешения споров, связанных с нарушениями, возникающими в ходе использования земельных участков, например земель населенных пунктов с разрешенным использованием «под индивидуальное жилищное строительство» и расположенных на них объектов недвижимости, в частности - процедура перевода статуса объекта недвижимости. Так, до 2015 г. статус недвижимого объекта «квартира» при наличии градостроительной возможности изменялся в судебном порядке на статус «изолированная часть жилого дома» с возможностью последующего оформления обособленных прав на земельные участки в отношении лиц, являющихся собственниками изменяющегося объекта недвижимости. С 2015 г. «квартирный» статус может быть изменен исключительно на «часть жилого дома». В данном случае оформить право собственности на земельный участок без лиц, которые являются правообладателями смежных частей жилого дома, невозможно. 
Земельный участок в таком случае передается собственникам объекта недвижимости либо в общедолевую собственность, либо в аренду.

Перечень представленных примеров «правоприменительных изменений» в связи с земельно-правовым и градостроительным реформированием не является исчерпывающим. Анализ правоприменительной практики, проведенный с помощью систем поиска судебных актов ГАС «Правосудие», «Электронный страж», демонстрирует, что категории рассматриваемых в судах Российской Федерации земельных споров делятся на пять групп:

1. Споры о праве собственности на землю, например: о праве собственности на невостребованные земельные участки земель общего пользования, на земельные участки в порядке приобретательской давности, на садовые участки и объекты недвижимости, иные споры о праве собственности на землю.

2. Споры, связанные с землепользованием, то есть споры на самовольные постройки, об устранении препятствий в пользовании земельными участками и объектами недвижимости, о постановке (снятии) земельного участка на кадастровый учет, о границах земельного участка и правах на них, в том числе сопряженные со спорами о постановке (снятии) земельного участка на кадастровый учет, споры, связанные с защитой прав на землю, установлением фактов, имеющих юридическое значение.

3. Другие споры, связанные с землепользованием, например дела по искам СНТ к членам СНТ и другим лицам, связанные с членством и пользованием земельными участками, иные споры, возникающие по инициативе или с участием садоводов, СНТ, о признании недействительными ненормативных актов.

4. Споры, связанные с применением законодательства о земле - по делам об оспаривании ненормативных правовых актов, связанных с применением законодательства о земле, об изъятии, прекращении или ограничении права на земельный участок, о признании права собственности на землю, об истребовании земельного участка из чужого незаконного владения, об устранении нарушений прав собственника на землю, не связанных с лишением вла- дения, споры, возникающие в связи с неисполнением или ненадлежащим исполнением обязательств из совершения сделок с землей, из совершения с землей сделок купли-продажи, из совершения с землей сделок аренды.

5. Споры, связанные с признанием действий, бездействия, актов органов государственной власти и местного самоуправления незаконными, в том числе споры по арендной и кадастровой стоимости земельных участков, налоговому обременению.

Анализ видового разнообразия земельных споров, даже на первый взгляд, демонстрирует их сложность, необходимость использования при разрешении специальных органов и познаний, так как разобраться в тонкостях землепользования не всегда просто даже специалистам. Например, мировой опыт разрешения земельных споров базируется на судебной и административной практике споров, связанных с землепользованием. «В Англии разрешением земельных споров занимаются несколько органов, наделенных такими полномочиями (суды графств - территориальные суды). В США основной объем земельных споров рассматривается судами общей юрисдикции (районные, окружные, апелляционные, высшие). В отдельных штатах были созданы специальные судебные органы, призванные решать земельные споры. Во Франции разрешением споров в области земельных правоотношений наделены паритетные трибуналы по земельной аренде - земельные суды. В Германии, Австрии, Швейцарии и Лихтенштейне с 1877 года существует земельный суд, имеющий в подчинении несколько окружных судов, расположенных на его территории. В Австралии (штат Новый Южный Уэльс) в 1980 году основан Земельный суд, который является специальным судом» [15].

В Российской Федерации специализированных земельных судов не учреждено, согласно ст. 64 ЗК РФ земельные споры разрешаются в судебном порядке, но до принятия дела к производству земельный спор может быть передан сторонами на разрешение в третейский суд при наличии заключенного между ними третейского соглашения. При таких обстоятельствах еще в 2014 г. эксперты стали говорить о необходимости дополнительной подготовки и специализации судебного корпу- 
ca, создания специализированных судов, особенно в стратегически важных направлениях (агробизнес) [9] (уже созданы по рассмотрению конфликтов в сфере авторского и информационного права). Такой подход, на первый взгляд, оправдан, помимо вышеизложенного, уже имеющимся в России опытом. Например, в период столыпинской реформы «земельные вопросы» рассматривались специализированными органами - уездными земельными комиссиями. Разрешение земельных споров аналогичными органами закреплялось и положениями Земельного кодекса 1922 г. (упразднены с разделением компетенций между сельсоветом, райисполкомом, общественными и народными судами в 1930 г.). Судебная практика разрешения споров в связи с принятием Земельного кодекса 1991 г. фактически (соответствующая глава в законе присутствовала) не действовала на основании Указа Президента РФ от 24 декабря 1993 г. № 2287. В 2001 г. судебное разрешение земельных споров возобновилось, что было закреплено в Земельном кодексе РФ, однако суда по разрешению земельных споров создано не было. На наш взгляд, к современным специализированным инстанциям следует отнести комиссии по разрешению споров о результатах определения кадастровой стоимости, созданные при Росреестре с 2012 г. в целях реализации положений ст. 24.18 Федерального закона от 29 июля 1998 г. № 135-Ф3 «Об оценочной деятельности в Российской Федерации». Вместе с тем полагаем, что к вопросу о создании специализированной судебной инстанции по разрешению земельных споров переходить преждевременно, так как их видовое многообразие свидетельствует о правоприменительном «смешении» предметов и оснований земельных споров со спорами в других отраслях, где правоприменители должны обладать широким спектром компетенций, не ограниченных земельными вопросами. Представляется значимым, ввиду отсутствия в современной российской правоприменительной практике специализированного «земельного» суда либо иного органа по разрешению земельных споров, помимо споров о кадастровой стоимости земельных участков, разрешать споры, связанные с землепользованием, путем привлечения сторонами спора квалифицированной по- мощи. Объективно, что «спорящие стороны», не обладая специальными познаниями и необходимым опытом разрешения земельноправовых конфликтов, без привлечения квалифицированной помощи в своих интересах разрешить их не смогут, а защита прав и свобод граждан в земельных вопросах должна быть качественной и эффективной.

Значение термина «квалифицированный», по мнению Т.Ф. Ефремова, состоит в обладании специальными знаниями, навыками, умением, опытом [5]. Вместе с тем исследования «квалификации» (квалификация - от лат. qualis - какой по качеству и facio - делаю, от англ. quality - качество, степень проявления достоинств) как правового явления велись и ведутся в границах оценки правонарушений и преступлений. Так, теоретики в области права (А.И. Рарог, А.Н. Бабай, А.В. Нечепурнов, Е.В. Чвялева, А.А. Гуничев, А.П. Коробов) под квалификацией (юридической, правовой) понимают выявление и оценку совокупности фактических обстоятельств дела путем их соотнесения с определенными юридическими нормами. Однако в качестве предиката «квалифицированный» мы можем встретить среди юридических терминов более широкой проблематики - квалифицированное преступление, квалифицированный состав, квалифицированная электронная подпись, правовая квалификация. В связи с этим полагаем, что в земельном правоприменении «квалификация» есть наличие необходимых знаний и опыта в разрешении земельных конфликтов. Квалифицированную помощь при этом могут оказывать специалисты в области земельных вопросов (кадастровые инженеры, специалисты органов государственной власти и местного самоуправления, эксперты для дачи соответствующих заключений) и права (юрисконсульты, адвокаты, нотариусы). Последние обеспечивают юридическую помощь, представляющую вид квалифицированной помощи.

Интерес к понятию «юридическая помощь» достаточно широк, вместе с тем считаем, что его трактовки очень схожи и в целом отражают обеспечение доступа к правосудию, защите законных прав и интересов физических, юридических лиц. Сущность юридической помощи варьируется и определяется как деятельность (Н.С. Амельков) [1], как 
система мероприятий (В.И. Качалов) [8], как сложная и согласованная совокупность большого количества составляющих, к которым относятся предмет, субъекты, цели, а также качество помощи в юридической сфере (А.Л. Миронов) [12]. К составляющим юридической помощи Федеральный закон от 31 мая 2002 г. № 63-Ф3 «Об адвокатской деятельности и адвокатуре в Российской Федерации» (ст. 2) относит дачу консультаций, справок по правовым вопросам, составлению документов правового характера; представление интересов доверителя в конституционном, гражданском, административном судопроизводстве; участие в качестве представителя или защитника доверителя в уголовном судопроизводстве и производстве по делам об административных правонарушениях; участие в качестве представителя доверителя в разбирательстве дел в третейском суде, международном коммерческом арбитраже (суде) и иных органах разрешения конфликтов, в органах государственной власти и местного самоуправления, общественных объединениях и иных организациях, в том числе международных, в исполнительном производстве, а также при исполнении уголовного наказания, в налоговых правоотношениях; иную юридическую помощь, не запрещенную федеральным законом.

Понятие «квалифицированная юридическая помощь» имеет «отечественную правовую основу... является детищем российского законодателя» [10]. Квалифицированная юридическая помощь в Российской Федерации гарантируется (ст. 48 Конституции РФ), вместе с тем теоретико-правовые проблемы ее правового регулирования обусловлены недостаточным осмыслением на доктринальном уровне понятий «квалифицированная юридическая помощь», а также «право на квалифицированную юридическую помощь» [11].

Говоря о квалифицированной юридической помощи, основным смысловым зерном является именно субъект, ее оказывающий. Федеральный закон «Об адвокатской деятельности и адвокатуре в Российской Федерации» соотносит квалифицированную юридическую помощь с адвокатской деятельностью, оказываемой лицами, получившими статус адвоката, на профессиональной основе. Однако, по мнению Н.А. Баевой, не следует отождествлять адвокатскую деятельность и оказание квалифицированной юридической помощи, поскольку первое является лишь разновидностью или формой второго [2]. А.В. Закомолдин под субъектами, оказывающими юридическую помощь, понимает профессиональных юристов [6]. О.В. Невская с квалифицированной юридической помощью соотносит «деятельность лиц, обладающих специальными познаниями в области права, по оказанию качественных правовых услуг» [13]. До сих пор не получивший законную силу проект Федерального закона «Об оказании квалифицированной юридической помощи в Российской Федерации» (ст. 2) под квалифицированной юридической помощью определяет любую самостоятельную деятельность по предоставлению на постоянной профессиональной основе юридических услуг на территории Российской Федерации. Вместе с тем Министерство юстиции РФ в октябре 2017 г. официально представило проект Концепции регулирования рынка профессиональной юридической помощи, содержащей планы установления адвокатской монополии на оказание юридических услуг к 1 январю 2023 года. С этой даты юридическую помощь в РФ на возмездной основе вправе будут оказывать только адвокаты и адвокатские образования, и лишь адвокаты смогут осуществлять представительство во всех судебных инстанциях (последнее положение не будет распространяться на корпоративных юристов в случае представления ими в судах интересов своих работодателей).

Говоря о монополии адвокатской деятельности в оказании квалифицированной юридической помощи, считаем необходимым ее распространение на судебное представительство. Вместе с тем, в то время как граждане и юридические лица в области земельно-правовых отношений все чаще нуждаются в квалифицированной юридической помощи, представляется, что перечень специалистов, имеющих необходимые познания в области земельных правоотношений, нельзя ограничивать такими субъектами, как адвокаты. Государственные, муниципальные служащие специализированных отделов и направлений деятельности, имеющие юридическое образование, обладая информацией ограниченного пользования, либо вы- 
даваемой за плату (в области градостроительства, кадастровой деятельности, землепользовании и др.), в соответствии с их должностными обязанностями осуществляют юридическое консультирование, дают правовую оценку документам, оказывают иную квалифицированную юридическую помощь. К лицам, оказывающим квалифицированную юридическую помощь по вопросам наследования и регистрации сделок с объектами недвижимости в области земельных правоотношений, можно отнести и нотариусов.

Насколько востребована квалифицированная юридическая помощь в земельных вопроcax? За получением квалифицированной юридической помощи по разрешению земельных споров граждане и юридические лица прибегают в большинстве случаев, но не всегда, в большей степени ввиду ее высокой стоимости, которая объективно складывается из затрат на сбор документов, необходимых заключений специалистов и экспертов, оплаты услуг представителя, судебных расходов. Однако ввиду отсутствия специальных познаний риск недостижения желаемого результата для стороны земельного спора повышается. В этой связи положительным законодательным опытом можно назвать установленную законом возможность получения гражданами квалифицированной юридической помощи бесплатно. Например, к случаям оказания юридической помощи бесплатно на территории Волгоградской области в соответствии с Законом Волгоградской области от 10 июля 2015 г. № 107-ОД «О бесплатной юридической помощи на территории Волгоградской области» отнесены правовое консультирование, составление документов правового характера, защита прав на земельные участки, если на них расположено единственное жилое помещение, а также оспаривание актов, действий, бездействия органов государственной власти и местного самоуправления во внесудебном порядке, что направлено на эффективную защиту такого основополагающего права человека, как право на жилище, закрепленное ст. 40 Конституции РФ.

\section{Заключение}

Таким образом, в разрешении споров, связанных с землепользованием, защита (представительство) прав и законных интересов физических и юридических лиц лежит именно на корпоративных юристах и адвокатах, а квалифицированная помощь обеспечивается специалистами, имеющими теоретический и практический опыт в области землепользования.

\section{СПИСОК ЛИТЕРАТУРЫ}

1. Амельков, Н. С. Понятие квалифицированной юридической помощи в уголовном судопроизводстве России / Н. С. Амельков // Молодой ученый. - 2013. - № 6. - С. 525-529.

2. Баева, Н. А. Конфликты в деятельности адвоката - защитника в российском уголовном судопроизводстве : автореф. дис. ... канд. юрид. наук / Баева Наталья Алексеевна. - Воронеж, 2007. - 24 с.

3. Градостроительный кодекс Российской Федерации от 29.12.2004 № 190-Ф3 (ред. от 23.04.2018) // Собрание законодательства РФ. 2018. - № 18 ( 30 апр.). - Ст. 2559.

4. Гражданский кодекс Российской Федерации (часть первая) от 30.11.1994№ 51-Ф3(ред. от 23.05.2018) (с изм. и доп., вступ. в силу с 03.06.2018) // Собрание законодательства РФ. - 2018. - № 22 (28 мая). - Ст. 3040.

5. Ефремов, Т. Ф. Новый словарь русского языка. Толково-словообразовательный / Т. Ф. Ефремов. - М. : Русский язык, 2000.

6. Закомолдин, А. В. Квалифицированная юридическая помощь в уголовном процессе России : понятие, содержание, гарантии : автореф. дис. ... канд. юрид. наук / Закомолдин Алексей Валериевич. - Самара, 2007. - 22 c.

7. Земельный Кодекс РФ от 25.10.2001 № 136Ф3 (ред. от 31.12.2018). - Доступ из справ.-правовой системы «КонсультантПлюс».

8. Качалов, В. И. Оказание юридической помощи населению в Российской Федерации / В. И. Качалов. - М. : Московский государственный индустриальный университет, 2007. -227 с.

9. Колодина, И. Земля вызывает Фемиду / И. Колодина // Российская Бизнес-газета - Бизнес и власть . - 2014. - 13 мая. - № 947 (18) .

10. Косолапова, Н. А. Право на квалифицированную юридическую помощь в конституционном судебном процессе : автореф. дис. ... канд. юрид. наук / Косолапова Наталья Александровна. - Белгород, 2016. $-21 \mathrm{c}$.

11. Кузнецова, С. Д. К вопросу о понятии права на квалифицированную юридическую помощь / С. Д. Кузнецова // Актуальные вопросы юриспруденции : сб. науч. тр. по итогам Междунар. науч.практ. конф. № 2. - Екатеринбург, 2015. - 60 с. 
12. Миронов, А. Л. Конституционно-правовое регулирование права на юридическую помощь / А. Л. Миронов // Вестник Московского университета МВД России. - 2012. - С. 159-161.

13. Невская, О. В. Что такое квалифицированная юридическая помощь? / О. В. Невская // Адвокат. - 2004. - № 11. - С. 37-39.

14. Постановление Пленума Верховного Суда Российской Федерации № 10, Пленума Высшего Арбитражного Суда Российской Федерации № 22 от 29 апреля 2010 г. «О некоторых вопросах, возникающих в судебной практике при разрешении споров, связанных с защитой права собственности и других вещных прав». - Доступ из справочно-правовой системы «КонсультантПлюс».

15. Самойлова, Д. Земельные споры в России и за рубежом / Д. Самойлова // ЭЖ-Юрист. - 2016. № 30 (август).

16. Федеральный закон от 24.07.2007 № 221-Ф3 «О кадастровой деятельности» (ред. от 28.02.2018) // Собрание законодательства РФ. - 2017. - 30 июля (№ 31). - Ст. 4017 ; 2018. - 5 марта (№ 10). - Ст. 1437.

17. Федеральный закон от 13.07.2015 года № 218-Ф3 «О государственной регистрации недвижимости» (ред. от 03.04.2018) // Собрание законодательства РФ. - 2015. - 20 июля (№ 29 (Ч. 1)). Ст. 4344 ; 2018. - 9 апреля (№ 15 (Ч. 1)). - Ст. 2031.

\section{REFERENCES}

1. Amelkov N.S. Ponyatie kvalifitsirovannoy yuridicheskoy pomoshchi $\mathrm{V}$ ugolovnom sudoproizvodstve Rossii [The Concept of Qualified Legal Assistance in Criminal Proceedings in Russia]. Molodoy uchenyy, 2013, no. 6, pp. 525-529.

2. Baeva N.A. Konflikty $v$ deyatelnosti advokata - zashchitnika v rossiyskom ugolovnom sudoproizvodstve: avtoref. dis. ... kand. yurid. nauk [Conflicts in theActivities of a Lawyer - Defender in Russian Criminal Proceedings. Cand. jurid. sci. abs. diss.]. Voronezh, 2007. 24 p.

3. Gradostroitelnyy kodeks Rossiyskoy Federatsii ot 29.12.2004 № 190-FZ (red. ot 23.04.2018) [Urban Planning Code of the Russian Federation Dated 29 Dec. 2004 No. 190-FZ (Amend. of 23 Apr. 2018)]. Sobranie zakonodatelstva RF, 2018, no. 18, art. 2559.

4. Grazhdanskiy kodeks Rossiyskoy Federatsii (chast pervaya) ot 30.11.1994 № 51-FZ (red. ot 23.05.2018, s izm. i dop., vstup. v silu s 03.06.2018) [Civil Code of the Russian Federation (Part One) Dated 30 Nov. 1994 No. 51-FZ (Amend. of 23 May 2018) (as Amended Effective of 03 June 2018)]. Sobranie zakonodatelstva RF, 2018, no. 22, art. 3040.

5. Efremov T.F. Novyy slovar russkogo yazyka. Tolkovo-slovoobrazovatelnyy [New Dictionary of the
Russian Language. Explanatory and Word-Formative.]. Moscow, Russkiy yazyk Publ., 2000.

6. Zakomoldin A.V. Kvalifitsirovannaya yuridicheskaya pomoshch $v$ ugolovnom protsesse Rossii: ponyatie, soderzhanie, garantii: avtoref. dis. ... kand. yurid. nauk [Qualified Legal Assistance in the Criminal Process of Russia: Concept, Content, Guarantees. Cand. jurid. sci. abs. diss.]. Samara, 2007. 22 p.

7. Zemelnyy Kodeks RF ot 25.10.2001 № 136-FZ (red. ot 31.12.2017) [Land Code of the Russian Federation Dated 25 Oct. 2001 No. 136-FZ (as Amend. of 31 Dec. 2018).]. Access from Reference Legal System 'Consultant Plus'.

8. Kachalov V.I. Okazanie yuridicheskoy pomoshchi naseleniyu $v$ Rossiyskoy Federatsii [Providing the Population of the Russian Federation with Legal Assistance]. Moscow, Moskovskiy gosudarstvennyy industrialnyy universitet Publ., 2007. 227 p

9. Kolodina I. Zemlya vyzyvaet Femidu [The Earth Calls Themis]. Rossiyskaya Biznes-gazetaBiznes $i$ vlast, 2014, no. 947 (18).

10. Kosolapova N.A. Pravo na kvalifitsirovannuyu yuridicheskuyu pomoshch $v$ konstitutsionnom sudebnom protsesse: avtoref. dis. ... kand. yurid. nauk [The Right to Qualified Legal Assistance in the Constitutional Judicial Process. Cand. jurid. sci. abs. diss.]. Belgorod, 2016. 21 p.

11. Kuznetsova S.D. K voprosu o ponyatii prava na kvalifitsirovannuyu yuridicheskuyu pomoshch [On the Issue of the Concept of the Right to Qualified Legal Assistance]. Aktualnye voprosy yurisprudentsii: sb. nauch. tr. po itogam Mezhdunar. nauch.-prakt. konf. № 2. Ekaterinburg, 2015.60 p.

12. Mironov A.L. Konstitutsionno-pravovoe regulirovanie prava na yuridicheskuyu pomoshch [Constitutional and Legal Regulation of the Right to Legal Assistance]. Vestnik Moskovskogo universiteta MVD Rossii, 2012, pp. 159-161.

13. Nevskaya O.V. Chto takoe kvalifitsirovannaya yuridicheskaya pomoshch [What is Qualified Legal Assistance]. Advokat, 2004, no. 11, pp. 37-39.

14. Postanovlenie Plenuma Verkhovnogo Suda Rossiyskoy Federatsii № 10, Plenuma Vysshego Arbitrazhnogo Suda Rossiyskoy Federatsii № 22 ot 29 aprelya 2010 g. "O nekotorykh voprosakh, voznikayushchikh $v$ sudebnoy praktike pri razreshenii sporov, svyazannykh s zashchitoy prava sobstvennosti $i$ drugikh veshchnykh prav» [Resolution of the Plenum of the Supreme Court of the Russian Federation No. 10, Plenum of the Supreme Arbitration Court of the Russian Federation No. 22 Dated April 29, 2010 “On Certain Issues Arising in Judicial Practice while Solving Disputes Related Protecting Property Rights and Other Real Rights"]. 


\section{ГЛАВНАЯ ТЕМА НОМЕРА}

Access from Reference Legal System 'Consultant Plus'.

15. Samoylova D. Zemelnye spory v Rossii i za rubezhom [Land Disputes in Russia and Abroad]. EZhYurist, 2016, no. 30.

16. Federalnyy zakon ot 24.07.2007 № 221-FZ «O kadastrovoy deyatelnosti» (red. ot 28.02.2018) [Federal Law Dated 24 July 2007 No. 221-FZ "On Cadastral Activities" (Amend. of 28 Feb 2018)].
Sobranie zakonodatelstva RF, 2017, July 30, no. 31, art. 4017; 2018, March 5, no. 10, art. 1437.

17. Federalnyy zakon ot 13.07.2015 goda № 218-FZ «O gosudarstvennoy registratsii nedvizhimosti» (red. ot 03.04.2018) [Federal Law Dated 13 July 2015 No. 218-FZ "On State Registration of Real Estate" (Amend. of 03 Apr. 2018)]. Sobranie zakonodatelstva $R F, 2015$, July 20, no. 29 (part 1), art. 4344; 2018, April 9, no. 15 (part 1), art. 2031.

\section{Information about the Authors}

Oksana I. Sharno, Candidate of Sciences (Jurispudence), Associate Professor, Department of Constitutional and Municipal Law, Volgograd State University, Prosp. Universitetsky, 100, 400062 Volgograd, Russian Federation, sharnoksana@yandex.ru, https://orcid.org/0000-0001-8892-1848

Anna Yu. Chikildina, Candidate of Sciences (Jurispudence), Associate Professor, Department of Constitutional and Administrative Law, Volgograd Institute of Management - Branch of the Russian Presidential Academy of National Economy and Public Administration, Gagarina St., 8, 400131 Volgograd, Russian Federation, chikildinaanna@yandex.ru, https://orcid.org/0000-0003-1694-5618

\section{Информация об авторах}

Оксана Игоревна Шарно, кандидат юридических наук, доцент кафедры конституционного и муниципального права, Волгоградский государственный университет, просп. Университетский, 100, 400062 г. Волгоград, Российская Федерация, sharnoksana@yandex.ru, https://orcid.org/ 0000-0001-8892-1848

Анна Юрьевна Чикильдина, кандидат юридических наук, доцент кафедры конституционного и административного права, Волгоградский институт управления - филиал РАНХиГС, ул. Гагарина, 8, 400131 г. Волгоград, Российская Федерация, chikildinaanna@yandex.ru, https:// orcid.org/0000-0003-1694-5618 